\title{
Effect of biomass blending on coal ignition and burnout during oxy-fuel combustion
}

B. Arias, C. Pevida, F. Rubiera, J.J. Pis

Instituto Nacional del Carbón, CSIC. Apartado 73. 33080 Oviedo, Spain

\begin{abstract}
Oxy-fuel combustion is a GHG abatement technology in which coal is burned using a mixture of oxygen and recycled flue gas, to obtain a rich stream of $\mathrm{CO}_{2}$ ready for sequestration. An entrained flow reactor was used in this work to study the ignition and burnout of coals and blends with biomass under oxy-fuel conditions. Mixtures of $\mathrm{CO}_{2} / \mathrm{O}_{2}$ of different concentrations were used and compared with air as reference. A worsening of the ignition temperature was detected in $\mathrm{CO}_{2} / \mathrm{O}_{2}$ mixtures when the oxygen concentration was the same as that of the air. However, at an oxygen concentration of $30 \%$ or higher, an improvement in ignition was observed. The blending of biomass clearly improves the ignition properties of coal in air. The burnout of coals and blends with a mixture of $79 \% \mathrm{CO}_{2}-21 \% \mathrm{O}_{2}$ is lower than in air, but an improvement is achieved when the oxygen concentration is 30 or $35 \%$. The results of this work indicate that coal burnout can be improved by blending biomass in $\mathrm{CO}_{2} / \mathrm{O}_{2}$ mixtures.
\end{abstract}

Keywords: Oxy-combustion, biomass, ignition, burnout.

\section{Introduction}

Nowadays, there is a general consensus that global warming and the increase in greenhouse gas (GHG) emissions are linked. The abatement of GHG emissions and mitigation of the negative consequences derived from the climate change are now an urgent challenge. New regulations aimed at reducing GHG emissions are being introduced and a global effort, reflected in the Kyoto Protocol, is being made towards this end. The deteriorating environmental situation and the new regulations are leading to the development of new technologies in order to reduce these emissions, especially those regarding $\mathrm{CO}_{2}$, as this is the major contributor to the greenhouse effect.

Various solutions can be applied to reduce GHG emissions, such as improving energy efficiency, making use of renewable energy or introducing new transport measures. Energy production is one of the greatest contributors to greenhouse emissions, because $\mathrm{CO}_{2}$ is produced during the combustion of fossil fuels. Coal plays an important role in energy production and it is foreseen that its importance will increase in the future due to its abundant 
and widely distributed reserves. However, this fuel has the drawback of producing more $\mathrm{CO}_{2}$ per unit of energy than other fossil fuels. The implementation of capture technologies in coal fired power stations could have a significant effect on global GHG emissions in the near and medium term.

The main capture technologies can be classified into three groups: pre-combustion, postcombustion and oxy-fuel combustion [1]. Flue gases produced in conventional combustion power plants are characterised by the low concentration of $\mathrm{CO}_{2}$ due to the nitrogen present in the air. The recovery of $\mathrm{CO}_{2}$ from these diluted flue gases using post-combustion technologies entails high energy penalties. The use of oxy-fuel combustion avoids this drawback. With this technique, coal is burned using a mixture of oxygen of high purity $(<95 \%)$ and recycled flue gas (mainly $\mathrm{CO}_{2}$ and $\mathrm{H}_{2} \mathrm{O}$ ), thus generating after combustion a rich $\mathrm{CO}_{2}$ stream ready for sequestration. The purpose of recycling the flue gas is to reduce the combustion temperature and to carry the heat produced through the boiler. Oxy-combustion can be used in plants of new design or as a retrofit technology in existing power stations.

During oxy-combustion, the gas composition inside the boiler differs greatly from that of conventional combustion with air, and this affects different aspects of coal combustion. The elevated heat capacity of the gases and the lower gas flow in oxy-fuel combustion have a considerable effect on heat transfer [2]. The recirculation of the flue gases, including the NOx, and the absence of nitrogen has a significant influence on NOx emissions. Many researchers have investigated this problem and they have concluded that considerable reductions (up to $70 \%$ ) can be achieved with respect to conventional air combustion [3, 4, 5, 6].

Coal ignition and burnout is also modified when oxy-fuel combustion is used. The ignition of coal particles is an important factor to be considered in boiler design and for the stability of the combustion process. Research on coal ignition under $\mathrm{O}_{2} / \mathrm{CO}_{2}$ mixtures is scarce and more effort is needed in order to understand the factors that influence this process $[7,8]$. Coal ignition is a complex process that is influenced by the properties of the coal and the experimental technique used $[9,10]$. Several experimental equipments can be used to study this process, such as thermogravimetric analysers or entrained flow reactors. The latter are more suitable for studying the ignition in pulverized boilers, as they simulate combustion conditions more closely (i.e. particle residence time, heating rate). Coal reactivity during oxyfuel combustion influences the unburnt carbon in the fly ashes. Char reactivity has been studied by means of TG tests under $\mathrm{O}_{2} / \mathrm{CO}_{2}$ mixtures and it was concluded that $\mathrm{CO}_{2}$ has no influence on the mass loss rate of the samples [11, 12]. However, the combustion conditions in thermogravimetric tests (i.e., temperature and kinetic regime) differ greatly from those 
encountered in a pulverized combustor. Other researchers have studied the reactivity of coal chars in entrained flow reactors under rich oxygen conditions and high temperatures in order to obtain kinetic parameters $[13,14,15]$. These studies have shown that the char combustion rate increases with oxygen concentration and that char gasification with $\mathrm{CO}_{2}$ may be important under these experimental conditions. However, these studies were performed using low $\mathrm{CO}_{2}$ concentrations.

Another approach for reducing $\mathrm{CO}_{2}$ emissions is the use of renewable fuels such as biomass. This is considered a neutral carbon fuel because the carbon dioxide released during its utilisation is an integral part of the carbon cycle. Several alternatives have being proposed to increase the fraction of biomass in energy production. The direct cofiring of biomass with coal is one of the most promising technologies in the short term [16]. The combination of oxy-fuel combustion with biomass could be used as a sink for $\mathrm{CO}_{2}$, and would contribute to reducing the environmental effect of GHG. However, more knowledge about cofiring coal and biomass under oxy-fuel conditions is needed.

In this work an entrained flow reactor was used to study the combustibility of coal and blends with biomass under $\mathrm{O}_{2} / \mathrm{CO}_{2}$ mixtures. Ignition tests were conducted to assess the effect of $\mathrm{CO}_{2}$ on ignition behaviour. Additionally, combustion tests were also carried out in order to assess the effect of oxy-fuel conditions on the burnout of coal and biomass blends.

\section{Experimental}

In this work, four coals of different rank (GI, VL, DI, DA) and a biomass -Eucalyptus-(RE) were used. The individual fuels were ground and sieved to obtain a 75-150 $\mu \mathrm{m}$ particle size fraction. Proximate and ultimate analyses of the samples are presented in Table 1.

An entrained flow reactor (EFR) was used to study the ignition and combustibility behaviour of the samples at high heating rates and short residence times. A diagram of the experimental device employed is shown in Figure 1. The reactor has a reaction zone with a maximum length of $170 \mathrm{~cm}$ and an internal diameter of $4 \mathrm{~cm}$. The EFR is electrically heated and is able to work at a maximum temperature of $1100{ }^{\circ} \mathrm{C}$. Fuel samples were fed from a hopper and the mass flow was controlled using a mechanical feeding system. The samples were introduced through a cooled injector to ensure that the temperature did not exceed $100{ }^{\circ} \mathrm{C}$ before entering the reaction zone. The gases were preheated to the oven temperature before being introduced into the reactor through flow straighteners. The flow rates of $\mathrm{N}_{2}, \mathrm{CO}_{2}$ and $\mathrm{O}_{2}$ from the gas cylinders were controlled by mass flow controllers. A water-cooled collecting probe was inserted into the reaction chamber from below. Nitrogen was introduced at the top of this 
probe to quench the reaction products. Particles were removed by means of a cyclone and a filter, and the exhaust gases were monitored using a battery of analysers $\left(\mathrm{O}_{2}, \mathrm{CO}_{2}, \mathrm{CO}\right)$. During the ignition tests in the EFR, the reactor was heated at $15^{\circ} \mathrm{C} \mathrm{min}{ }^{-1}$ from 500 to $800{ }^{\circ} \mathrm{C}$. The gas flow used in these tests ensured a particle residence time of $2.5 \mathrm{~s}$ at $500{ }^{\circ} \mathrm{C}$, and the excess oxygen was fixed at a value of $100 \%$. A reactor temperature of $1000{ }^{\circ} \mathrm{C}$ was used during the combustion experiments of individual coals and blends. The particle residence time was adjusted to $2.5 \mathrm{~s}$ for the combustion tests. Four binary mixtures of $\mathrm{O}_{2}, \mathrm{~N}_{2}$ and $\mathrm{CO}_{2}$ were used to compare the behaviour of the fuels used. For the ignition and combustion tests, air $\left(79 \% \mathrm{~N}_{2}-21 \% \mathrm{O}_{2}\right)$ was taken as reference and three binary blends of $\mathrm{O}_{2}$ and $\mathrm{CO}_{2}$ were used $\left(79 \% \mathrm{CO}_{2}-21 \% \mathrm{O}_{2}, 70 \% \mathrm{CO}_{2}-30 \% \mathrm{O}_{2}\right.$ and $\left.65 \% \mathrm{CO}_{2}-35 \% \mathrm{O}_{2}\right)$.

\section{Results and discussion}

\section{Ignition tests}

Several techniques can be used to determine the ignition of the samples in an EFR. One of the most commonly used is based on direct observation of the ignition event $[17,18,19]$. The other techniques are based on monitoring the evolution of the gases during coal particle ignition [20, 21]. In this work the second approach was employed. There is no general consensus for the definition of ignition temperature. The criterion used in this work was described in a previous paper [22]. In brief, the first derivative curves of the gas compositions were calculated and normalised with respect to the maximum value. The ignition temperature was taken as the temperature where these curves reached a value of $10 \%$. For the ignition tests, coals VL and DA were used. Additionally, two binary blends of RE and DA were tested in order to study the effect of biomass blending on coal ignition. Figure 2 represents the $\mathrm{CO}_{2}$ derivative curves of coal VL under the four experimental conditions used.

The ignition temperatures of coals VL and DA are shown in Figure 3. As can be seen, there is a clear difference in ignition temperature for both coals. The ignition of the semi-anthracite, VL, occurs at higher temperatures in all the experimental conditions. During coal ignition, the reactivity of the coal plays an important role, as the heat is released faster when coal reactivity is higher. This explains the differences in ignition temperature between the two coals. When $\mathrm{N}_{2}$ is replaced by $\mathrm{CO}_{2}$, there is an increase in the ignition temperature, especially in the case of coal VL. Previous studies have shown a similar trend (Kiga, 1997; Molina, 2007). This phenomenon can be explained as being due to the difference in the specific heats of the gases. $\mathrm{CO}_{2}$ has a higher specific heat, and so more heat is needed to increase the temperature when coal is being oxidized during ignition. This causes a delay in ignition in rich $\mathrm{CO}_{2}$ 
atmospheres. Regarding the tests performed in mixtures of $\mathrm{O}_{2} / \mathrm{CO}_{2}$, a decrease in ignition temperature with an increase of $\mathrm{O}_{2}$ concentration was observed. This is because the reaction rate increases which in turn increases the release of heat. Thus, when the oxygen concentration is $30 \%$ or higher, the ignition temperatures of coals VL and DA are lower than in air.

Figure 4 shows the ignition temperature of coal DA and blends DA-RE. When coal DA is blended with biomass, there is an important reduction in the ignition temperature in air. This decrease is proportional to the amount of biomass in the blend. A reduction of $32{ }^{\circ} \mathrm{C}$ is achieved when coal DA is blended with $20 \%$ of RE. This decrease is due to the fact that biomass is a fuel with a high reactivity and a high volatile matter content. It therefore reacts faster and improves the ignition behaviour of coal DA. As the percentage of biomass increases, more heat is released and the reduction in the ignition temperature of the blend is more pronounced.

However, when the blends are tested in mixtures of $\mathrm{CO}_{2}$ and $\mathrm{O}_{2}$, only a small decrease in ignition temperature with respect to the individual coal is observed. This phenomenon is especially relevant for the blend with $10 \%$ biomass. The differences in ignition temperature displayed by the DA-RE blends in air and $\mathrm{CO}_{2} / \mathrm{O}_{2}$ mixtures could be attributed to the heating value of the fuels and the different specific heats of $\mathrm{CO}_{2}$ and $\mathrm{N}_{2}$. Biomass has a lower heating value than coal, and so less heat is generated during its oxidation in the ignition process. When $\mathrm{CO}_{2}$ is the major component in the surrounding gases, the heat released by the biomass present in the blend generates a small increase in the temperature of the gases and so the ignition properties of coal DA are less affected. However, during the ignition in air less heat is needed to increase the temperature of the surrounding gases and so the blended biomass has more influence on the ignition of coal DA.

\section{Combustion tests}

For the combustion tests, coals GI, VL, DI, DA, and DA-RE blends were used. Different coal mass flow rates were employed for each gas composition. Thus the coals were burned with various degrees of excess oxygen for each gas composition. In this work, the stoichiometric ratio was used to assess the excess oxygen during combustion. This parameter is defined as the ratio between the coal mass flow rate used and the stoichiometric value.

Figure 5 shows the burnouts of individual coals obtained under the different experimental conditions. The burnouts of coal DI and DA exhibits a similar behaviour with respect to the stoichiometric ratio. As expected, there is a worsening of coal burnout as the stoichiometric ratio increases because the availability of oxygen is more restricted. Under fuel lean 
conditions, the burnout curves of coals DA and DI show an asymptotic approach towards a value of $100 \%$. The plots of coals GI and VL show a similar shape. For these coals, burnout displays a linear dependence on the stoichiometric ratio in air and the $\mathrm{CO}_{2} / \mathrm{O}_{2}$ mixtures. Even under fuel lean conditions these high rank coals attained low burnouts, reflecting a lower reactivity than that of coals DI and DA.

To compare the different behaviour of the coals under the same experimental conditions, burnouts were interpolated at a stoichiometric ratio of 0.8 using the curves shown in Figure 5. The results calculated for the individual coals are shown in Figure 6. For all the studied coals, the burnout obtained with the mixture $79 \% \mathrm{CO}_{2}-21 \% \mathrm{O}_{2}$ is lower than that reached in air. This result is in agreement with the findings of other researchers using other experimental devices $[23,24,25,26]$. When $\mathrm{N}_{2}$ is replaced by $\mathrm{CO}_{2}$, the heat capacity of the gases increases and the particle temperature during combustion is lower. This effect reduces the combustion rate of the chars and there is a worsening of coal burnout. Additionally, ignition under these experimental conditions is delayed as was observed during the ignition tests, resulting in a shorter combustion time under this atmosphere $\left(79 \% \mathrm{CO}_{2}-21 \% \mathrm{O}_{2}\right)$. For the mixtures $70 \% \mathrm{CO}_{2^{-}}$ $30 \% \mathrm{O}_{2}$ and $65 \% \mathrm{CO}_{2}-35 \% \mathrm{O}_{2}$, coal burnout is higher than in air. In these cases the higher oxygen concentration increases the char combustion rate with respect to combustion in air. The improvement in burnout under high oxygen concentration is especially noticeable for the higher rank coals (GI, VL). However, coal DA and DI reach a high burnout in air, so there is less margin for improvement by increasing the oxygen concentration.

The same methodology was used for the DA-RE blends. Their burnouts were also determined at different stoichiometric ratios. Figure 7 shows the burnout of the DA-RE blends at a stoichiometric ratio of 0.8 . The burnout of the blends presents a similar behaviour to that of the individual coals under the different atmospheres studied. There is a decrease in burnout in comparison with air combustion when the blends are fired in a $79 \% \mathrm{CO}_{2}-21 \% \mathrm{O}_{2}$ mixture, and burnout improves under the $\mathrm{CO}_{2} / \mathrm{O}_{2}$ mixtures when the oxygen concentration is higher than in air. The burnout of the individual coal DA is similar to those corresponding to the DA-RE blends when they are fired in air. This indicates that the effect of blending has a low impact on burnout. In the case of the $79 \% \mathrm{CO}_{2}-21 \% \mathrm{O}_{2}$ and $70 \% \mathrm{CO}_{2}-30 \% \mathrm{O}_{2}$ mixtures, the burnout improves slightly when the proportion of biomass increases in the blend. More differences are observed under the atmosphere which has a concentration of $65 \% \mathrm{CO}_{2}-35 \% \mathrm{O}_{2}$; in this case, there is a clear improvement in burnout with the increase in the percentage of biomass.

When two fuels are fired as a blend, the burnout of each component may be different to that exhibited when they are burned individually. Coal combustibility may be modified due to 
different reasons when it is blended. One of these reasons is the modification of the oxygen and temperature profiles developed inside the reactor, depending on whether the coal is burned alone or as a blend. If the reactivities of each fuel are different, there will be differences on their profiles, as the more reactive fuel will react faster, thereby reducing oxygen concentration and increasing the temperature at the top of the reaction chamber. Any improvement in the burnout of the less reactive component will depend on the oxygen and temperature profiles in the reactor.

Biomass is more reactive than coal DA, for this reason, the burnout of the blend could be improved if coal DA were unaffected by the modification of oxygen and temperature profiles. However when the DA-RE blends are tested in air, there is no appreciable improvement in burnout. This indicates that biomass combustion affects the combustibility of coal DA, causing it to exhibit a lower burnout than when it is burned alone. The worsening of DA burnout could be attributed to the fact that the oxygen availability is more restricted during combustion of the blend. In the case of the $79 \% \mathrm{CO}_{2}-21 \% \mathrm{O}_{2}$ mixture, there is a slight improvement in burnout with blending. In this case any reduction in the availability of oxygen would have less effect on DA, as the combustibility of this coal is reduced, due to the high $\mathrm{CO}_{2}$ concentration. In the case of $70 \% \mathrm{CO}_{2}-30 \% \mathrm{O}_{2}$ and $65 \% \mathrm{CO}_{2}-35 \% \mathrm{O}_{2}$, more oxygen is available and so the burnout of coal DA can be expected to be less affected. As a result, the burnout of the blend improves. The enhancement is especially remarkable in combustion at concentrations of $35 \%$ oxygen.

\section{Conclusions}

The ignition of individual coals and blends with biomass was tested in an entrained flow reactor under oxy-fuel combustion conditions, at different oxygen concentrations. The ignition temperature of the individual coals showed a strong dependence on the composition of the atmosphere. The ignition of the samples under a mixture of $79 \% \mathrm{CO}_{2}-21 \% \mathrm{O}_{2}$ is delayed with respect to air and there is a shift to higher temperatures. Ignition takes place at lower temperatures than in air when the oxygen concentration in the $\mathrm{CO}_{2} / \mathrm{O}_{2}$ mixtures is $30 \%$ or higher. The ignition of a hvb coal (DA) in air is improved when it is blended with biomass. Under $\mathrm{CO}_{2} / \mathrm{O}_{2}$ mixtures, the ignition temperatures of the blends are close to those of the individual coals and show poor improvement.

The burnouts of individual coals and blends were determined under the same atmosphere concentrations. The burnouts of the samples with a mixture of $79 \% \mathrm{CO}_{2}-21 \% \mathrm{O}_{2}$ are lower than those conducted in air. When the oxygen concentration in the $\mathrm{CO}_{2} / \mathrm{O}_{2}$ mixtures is 
increased to a value of $30 \%$, the burnout is higher than in air. The blending of biomass has a low impact during combustion in air. However there is an improvement in the burnout of the blends under $\mathrm{CO}_{2} / \mathrm{O}_{2}$ mixtures at high oxygen concentrations. 


\section{References}

[1] Wall TF. "Combustion processes for carbon capture”. Proceedings of the Combustion Institute (2007), doi:10.1016/j.proci.2006.07.123

[2] Buhre BJP, Elliot LK, Sheng CD, Gupta RP, Wall TF. “Oxy-fuel combustion technology for coal-fired power generation”. Progress in Energy and Combustion Science 2005; 21: 283307.

[3] Hu YQ, Kobayashi N, Hasatani M. "Effects of coal properties on recycled-NOx reduction in coal combustion with $\mathrm{O}_{2}$ /recycled flue gas”. Energy Conversion and Management 2003; 44: 2331-2340.

[4] Hu YQ, Kobayashi N, Hasatani M. “The reduction of recycled-NOx in coal combustión with $\mathrm{O}_{2}$ /recycled flue gas under low recycling ratio”. Fuel 2001; 80: 1851-1855.

[5] Tan Y, Croiset E, Douglas MA, Thambimuthu KV. "Combustion characteristics of coal in a mixture of oxygen and recycled flue gas”. Fuel 2006; 85: 507-512.

[6] Okazaki K, Ando T. "NOx reduction mechanism in coal combustion with recycled $\mathrm{CO}_{2}$ ”. Energy 1997; 2/3: 207-215.

[7] Kiga T, Takano S, Kimura N, Omata K, Okawa M, Mori T, Kato M. "Characteristics of pulverized-coal combustion in the system of oxygen/recycled flue gas combustion”. Energy Conversion Management 1997; 38: 129-134.

[8] Molina A, Shaddix CR. "Ignition and devolatilisation of pulverized bituminous coal particles during oxygen/carbon dioxide coal combustion”. Proceedings of the Combustion Institute 2007; 21: 1905-1912.

[9] Essenhigh RH, Misra MK, Shaw DW. "Ignition of coal particles: A review”. Combustion and Flame 1989; 77: 3-30.

[10] Herbig C, Jess A. "Determination of reactivity and ignition behaviour of solid fuels based on combustion experiments under static and continuous flow conditions”. Fuel 2002; 81: 2387-2395.

[11] Várhegyi G, Szabó P, Jakab E, Till F. "Mathematical modelling of char reactivity in Ar$\mathrm{O}_{2}$ and $\mathrm{CO}_{2}-\mathrm{O}_{2}$ mixtures”. Energy \& Fuels 1996; 10: 1208-1214.

[12] Várhegy G, Till F. “Comparison of temperature-programmed char combustion in $\mathrm{CO}_{2}-\mathrm{O}_{2}$ and Ar- $\mathrm{O}_{2}$ mixtures at elevated pressure”. Energy \& Fuels 1999; 13: 539-540.

[13] Murphy JJ, Shaddix CR. "Combustion kinetics of coal chars in oxygen-enriched environments”. Combustion and Flame 2006; 144: 710-729. 
[14] Saito M, Sakadata M, Sato M, Soutome T, Murata H. "Combustion rates of pulverized coal particles in high-temperature/high-oxygen concentration atmosphere”. Combustion and Flame 1991; 87: 1-12.

[15] Shaddix CR, Murphy JJ. “Coal char combustion reactivity in oxy-fuel applications”. Twentieth Pittsburgh Coal Conference, 2003.

[16] Demirbas A. "Potential applications of renewable energy sources, biomass combustion problems in boiler power systems and combustion related environmental issues”. Progress in Energy and Combustion Science 2005; 31: 171-192.

[17] Wall TF, Gupta RP, Gururajan VS, Zhang D. “The ignition of coal particles”. Fuel 1991; 70: 1011-1016.

[18] Zhang D, Wall TF. "Ignition of coal particles: the influence of experimental technique”. Fuel 1994; 73: 1114-1119.

[19] Faúndez J, Arias B, Rubiera F, Arenillas A, García X, Gordon AL, Pis JJ. “Ignition characteristics of coal blends in an entrained flow furnace”. Fuel (accepted to be published).

[20] Wall TF, Phong-Anant D, Gururajan VS, Wibberley LJ, Tate A, Lucas J. "Indicators of ignition for clouds of pulverized coal”. Combustion and Flame 1988; 72: 111-118.

[21] Gomez CO, Vastola FJ. "Ignition and combustion of single coal and char particles”. Fuel 1985; 64: 558-563.

[22] Faúndez J, Arenillas A, Rubiera F, García X, Gordon AL, Pis JJ. “Ignition behaviour of different rank coals in an entrained flow reactor”. Fuel 2005; 84: 2172-2177.

[23] Liu H, Zailani R, Gibbs BM. “Comparisons of pulverized coal combustion in air and mixtures of $\mathrm{O}_{2} / \mathrm{CO}_{2}$ ". Fuel 2005; 84: 833-840.

[24] Liu H, Zailani R, Gibbs MB. "Pulverized coal combustion in air and in $\mathrm{O}_{2} / \mathrm{CO}_{2}$ mixtures with NOx recycle”. Fuel 2005; 84: 2109-2115.

[25] Wang CS, Berry GF, Chang KC, Wolsky AM. "Combustion of pulverized coal using waste carbon dioxide and oxygen”. Combustion and Flame 1988; 72: 301-310.

[26] Kimura N, Omata K, Kiga T, Takano S, Shikisima S. “The characteristics of pulverized coal combustion in $\mathrm{O}_{2} / \mathrm{CO}_{2}$ mixtures for $\mathrm{CO}_{2}$ recovery”. Energy Conversion Management 1995; 36: 805-808. 


\section{List of Tables}

Table 1. Proximate and ultimate analyses of the samples used

\section{List of Figures}

Figure 1. Schematic diagram of the experimental device.

Figure 2. Derivative curves of the $\mathrm{CO}_{2}$ concentration during the tests performed using coal VL.

Figure 3. Ignition temperatures of coals VL and DA.

Figure 4. Ignition temperatures of coal DA and blends DA-RE.

Figure 5. Burnouts of the individual coals at different fuel ratios.

Figure 6. Comparison of the individual coal burnouts at a fuel ratio of 0.8 .

Figure 7. Burnouts of DA-RE blends at a fuel ratio of 0.8 . 
Table 1. Proximate and ultimate analyses of the samples used

\begin{tabular}{|c|c|c|c|c|c|}
\hline & GI & VL & DI & DA & $\mathrm{RE}$ \\
\hline Rank & an & sa & lvb & hvb & --- \\
\hline \multicolumn{6}{|c|}{ Proximate analysis (\% db) } \\
\hline Ash & 7.8 & 8.0 & 5.5 & 10.7 & 0.6 \\
\hline V.M. & 4.3 & 9.8 & 15.9 & 31.7 & 83.7 \\
\hline F.C. * & 95.7 & 90.2 & 84.1 & 68.3 & 16.3 \\
\hline \multicolumn{6}{|c|}{ Ultimate analysis (\% daf) } \\
\hline $\mathrm{C}$ & 94.3 & 87.8 & 87.9 & 82.7 & 48.8 \\
\hline$\overline{\mathrm{H}}$ & 2.1 & 3.2 & 3.8 & 5.0 & 6.1 \\
\hline $\mathrm{N}$ & 0.9 & 1.7 & 1.6 & 0.8 & 0.2 \\
\hline $\mathrm{S}$ & 0.8 & 1.9 & 4.0 & 0.9 & 0.0 \\
\hline $\mathrm{O}^{*}$ & 1.9 & 5.4 & 2.7 & 10.6 & 44.9 \\
\hline
\end{tabular}

db: dry basis

daf: dry ash free basis

* by difference

an, anthracite; sa, semi-anthratice; lvb, low volatite bituminous coal; hvb, high volatile bituminous coal 
Feeding system

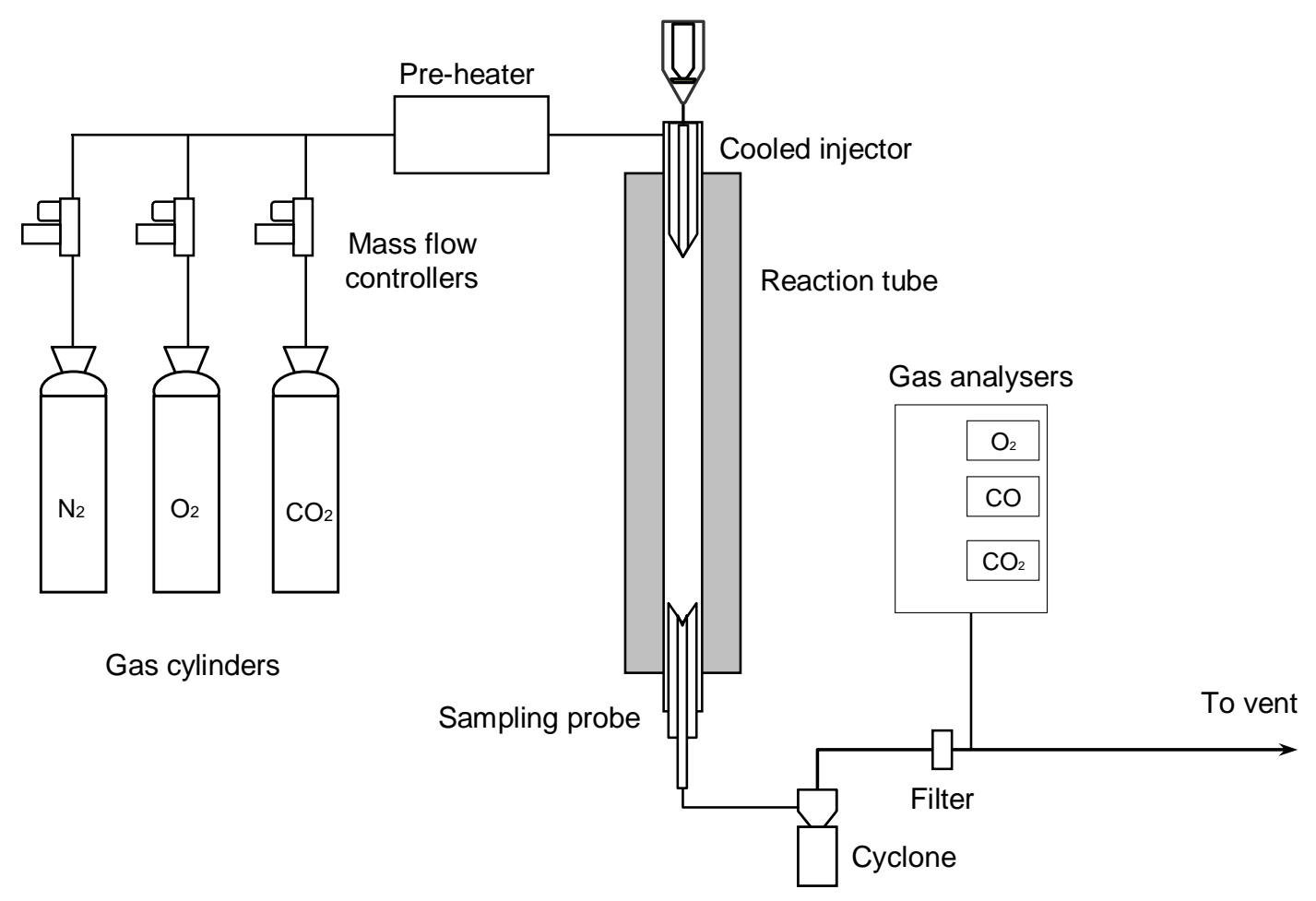

Figure 1. Schematic diagram of the experimental device. 


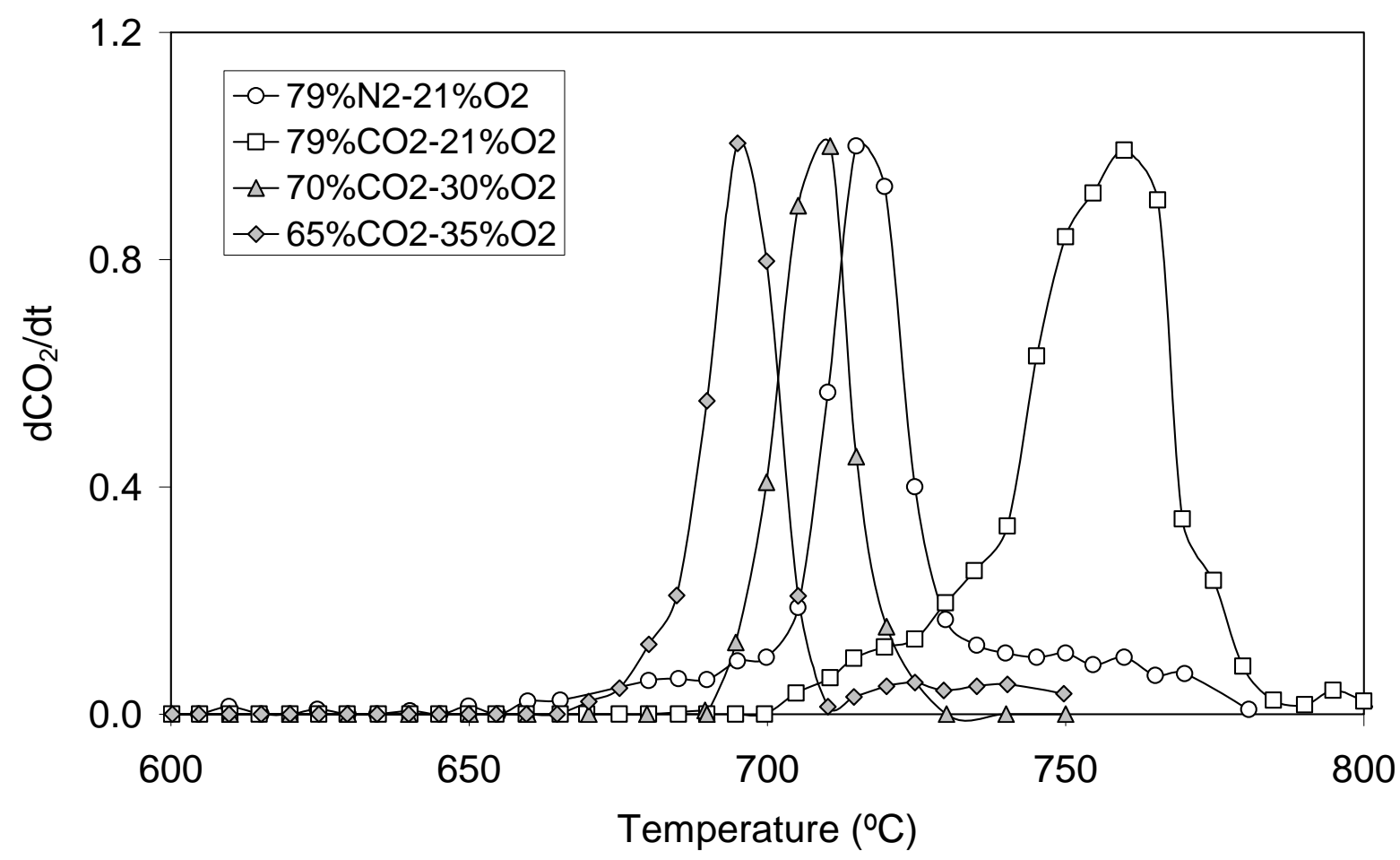

Figure 2. Derivative curves of the $\mathrm{CO}_{2}$ concentration during the tests performed using coal VL. 


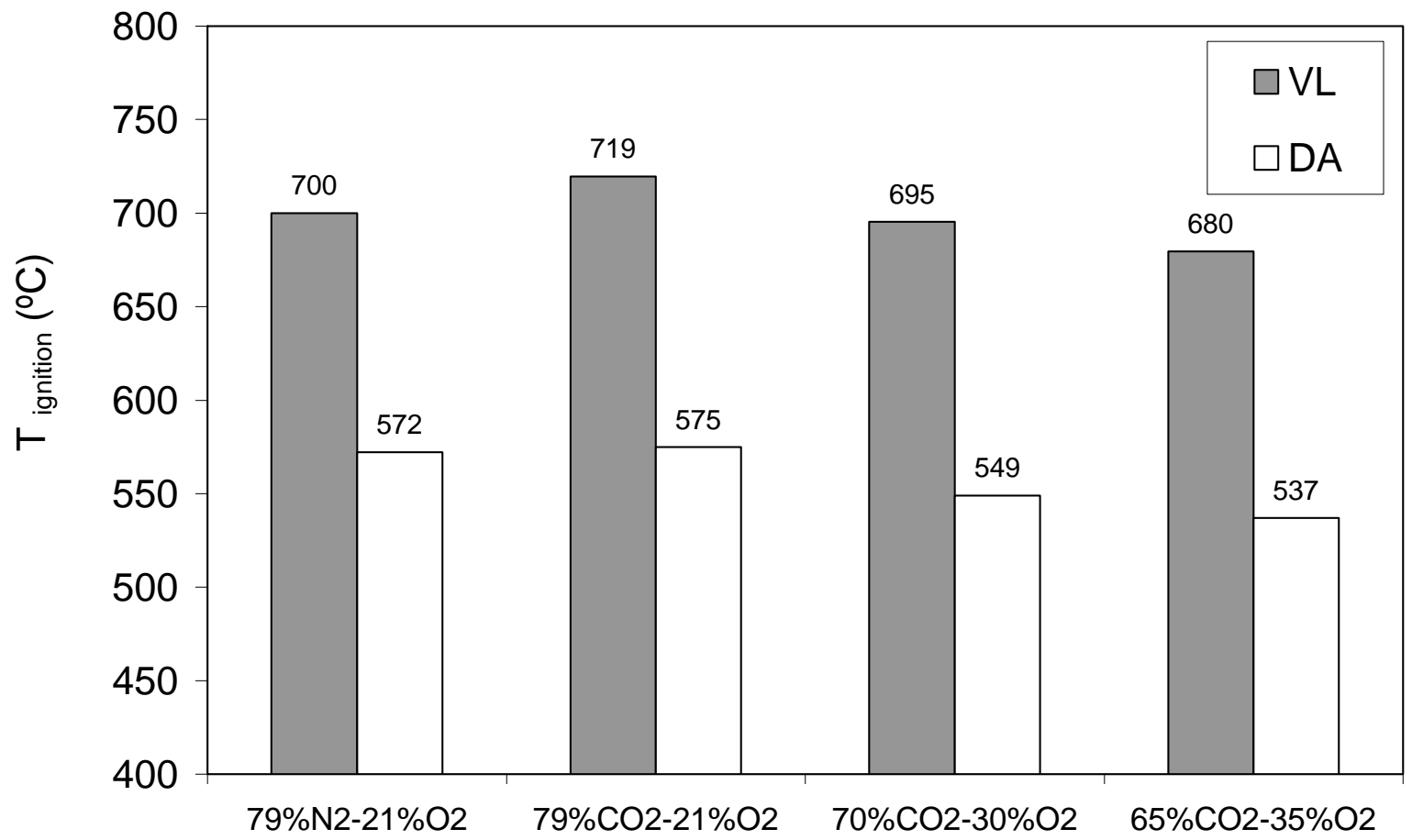

Figure 3. Ignition temperatures of coals VL and DA. 


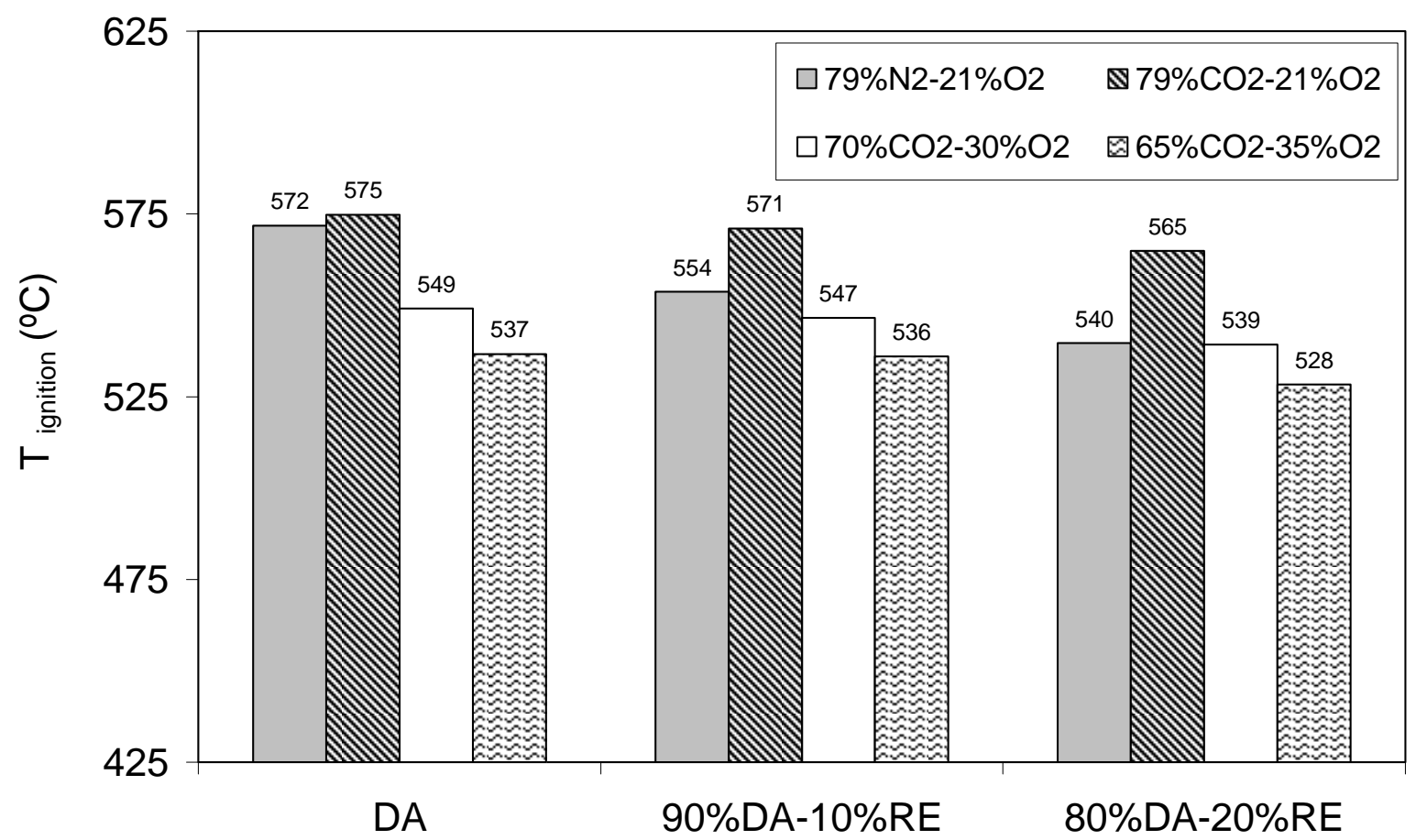

Figure 4. Ignition temperatures of coal DA and blends DA-RE. 

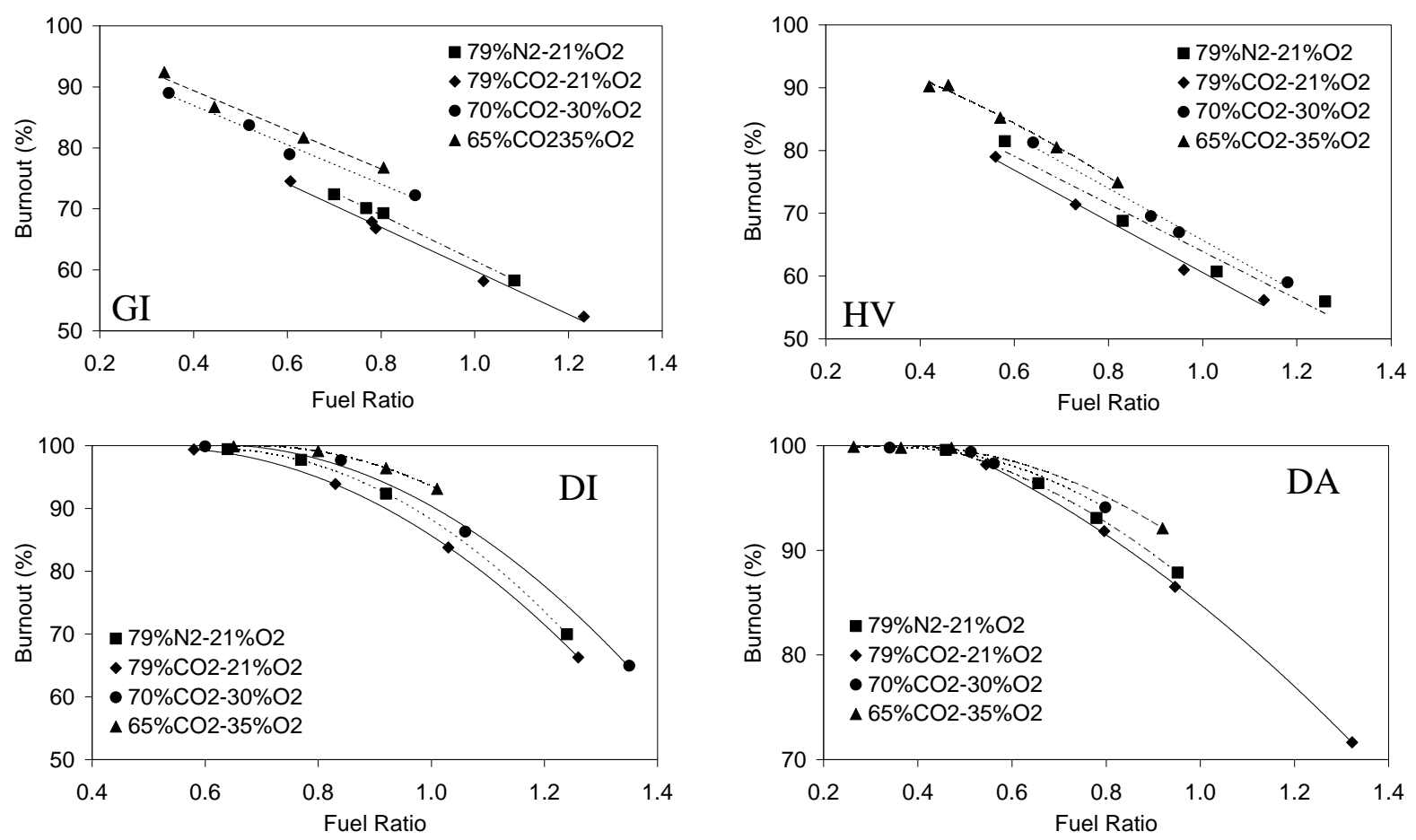

Figure 5. Burnouts of the individual coals at different fuel ratios. 


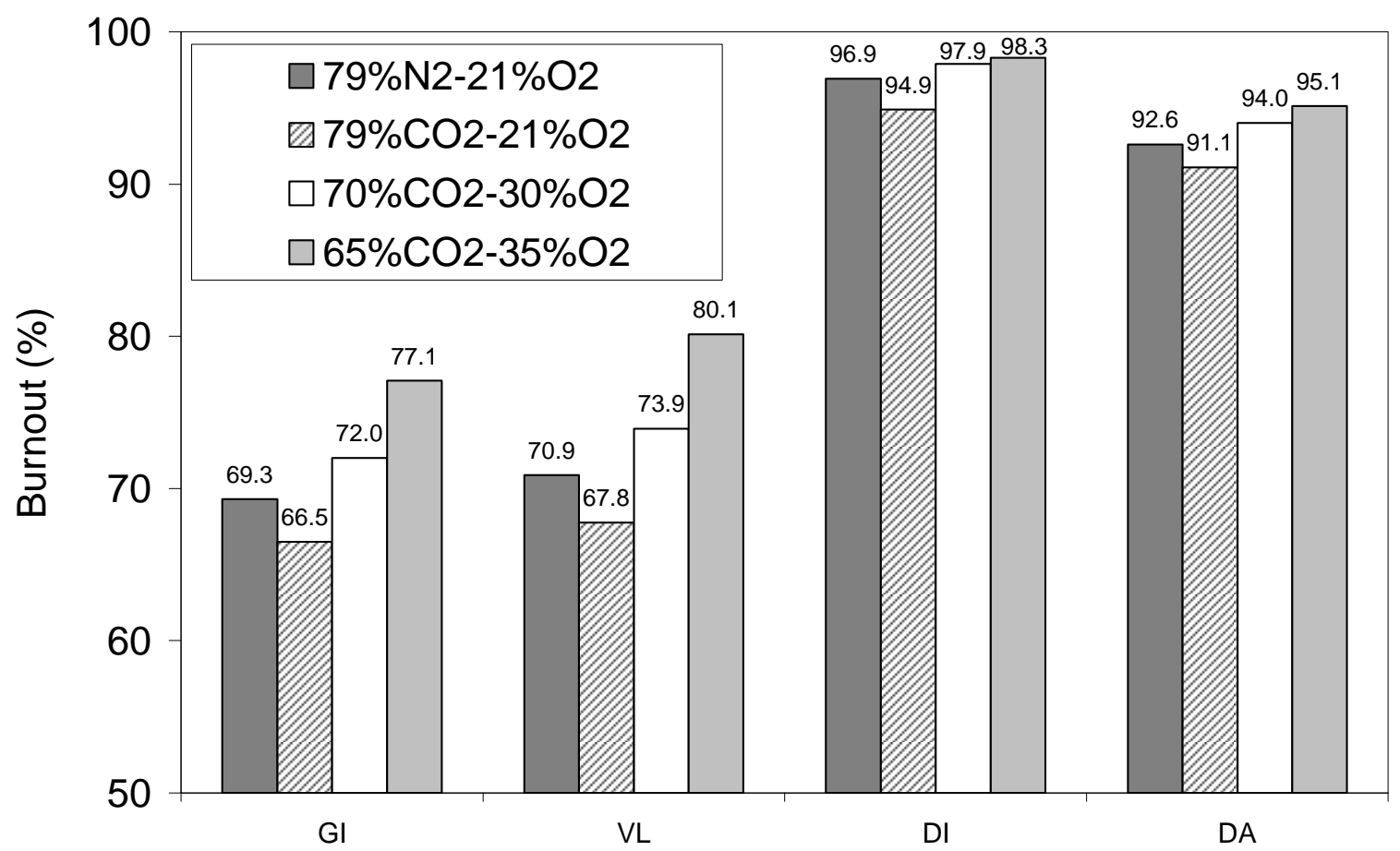

Figure 6. Comparison of the individual coal burnouts at a fuel ratio of 0.8 . 


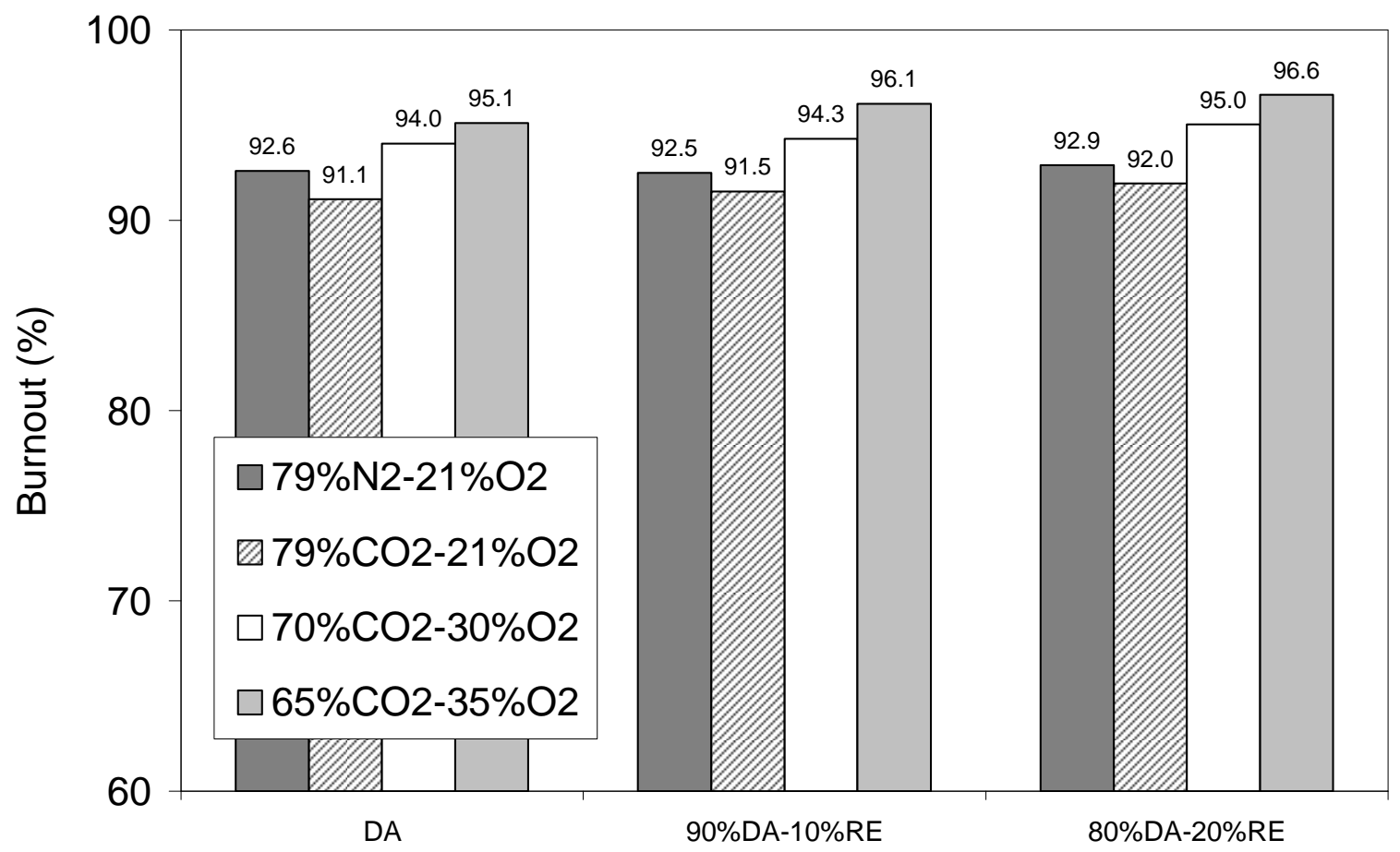

Figure 7. Burnouts of blends DA-RE at a fuel ratio of 0.8. 